\title{
US could be left behind
}

Washington

ALARMED by the absence of plans to build any major instruments for millimetrewavelength astronomy in the next decade, US astronomers are asking the National Science Foundation (NSF) to consider building them a new radiotelescope based on an array of millimetre-length antennas.

The telescope, expected to cost at least $\$ 20$ million, is essential if the United States is to beat off competition from Europe and Japan and maintain its lead in an area critical to the understanding of star formation and the evolution of galaxies, according to a panel led by Dr Alan Barrett of Massachusetts Institute of Technology. Without it, the panel warned the NSF astronomy advisory committee last week, millimetre-wavelength astronomy in the United States might wither away.

In asking for this kind of telescope - an aperture synthesis array - the community of millimetre-wavelength astronomers has swiftly changed horses. Until last year, when funding for the project collapsed, plans for the next decade of millimetrewavelength astronomy rested on the construction of a single-antenna 25-metre telescope proposed by the National Radio Astronomy Observatory. The panel claims that recent advances in the reliability of receivers have made an array of antennas, producing far better angular resolution, a more suitable option.

The request has come at a propitious moment for NSF. Astronomy is likely to be awash with dollars in the next few years following the 26 per cent funding increase it received in the administration's 1984 budget proposal.

Millimetre and sub-millimetre wavelength observations have been able to make major contributions to astronomy because these wavelengths penetrate the coldest and densest interstellar clouds. They can detect many atomic and molecular transitions which serve as probes to the physical conditions within the clouds. In the next ten years, the panel predicts, such observations will be critical to research on star formation and the evolution of galaxies.

The proposed telescope would consist of an aperture synthesis array with a minimum usable wavelength of $1 \mathrm{~mm}$, an angular resolution of one arc-second or better at a wavelength of $2.6 \mathrm{~mm}$ and a total geometrical collecting area of 1,000 to 2,000 square metres. For the time being, the panel is asking NSF only for a design study; construction would not begin for two years and the instrument would not begin to operate much before the end of the decade.

Approval of the panel's request cannot be regarded as a foregone conclusion, however. NSF director Ed Knapp told the astronomy advisory committee last week that astronomy's spectacular success in the 0028-0836/83/180007-01501.00
1984 budget apportionment had come about partly because of the astronomers' careful choice of priorities. NSF can be expected to look carefully at the possibility of US astronomers sharing international facilities.

The millimetre-wavelength panel maintains that no such facilities come near to meeting their requirements. In submillimetre astronomy, the future looks fairly bright, with new telescopes planned by Caltech and by Arizona University in association with the Max Planck Institute.

The Caltech project is still dependent on NSF funding approval; the Arizona telescope has already been promised state funds and money from the German Government. In millimetre-wavelength astronomy there are no suitable telescopes on the drawing board at all.

Some of the scientific problems confronting millimetre-wavelength astronomers could be tackled by using the Nobeyama Radio Observatory in Japan or the Institut de Radio Astronomie Millimétrique in Spain, the panel believes. But it says neither of these facilities of fer the right combination of wavelength coverage, sensitivity and speed.

Peter David

\section{Agricultural research}

\section{Australia woos developing countries}

\section{Canberra}

AUSTRALIA is embarking upon its strongest commitment yet to long-term aid in agricultural research for developing countries. The Australian Centre for International Agricultural Research (ACIAR), established in June last year as a statutory body responsible to the Minister for Foreign Affairs, has been given free rein for the next 10 years, after which its operations will be reviewed, with $A \$ 25$ million in the kitty for its first three years. Its funds are carved out of the foreign aid appropriation.

ACIAR's main role is to match research projects going on in institutions such as CSIRO, universities and state agricultural departments with the needs of developing countries. Beneficiaries will be, in the first instance, Australia's neighbours - South-East Asia and the South Pacific islands, particularly Papua New Guinea with which Australia has historical links.

The need for such an umbrella organization to coordinate agricultural aid, previously administered in an ad hoc fashion, was perceived by a study committee chaired by Sir John Crawford, chancellor of the Australian National University, and its inception was discussed as part of the North-South dialogue at the Commonwealth heads of government meeting in October 1981.

According to the then Minister for Foreign Affairs, Mr Anthony Street, when introducing the ACIAR Act, its charter is "to mobilize and expand Australia's research capacity so as to assist developing countries" and "not itself engage in research activities"'. ACIAR's first director, Professor R.J. McWilliam, stresses that it will not make grants and will not respond to individual applications. Rather, it will monitor research programmes in Australian institutions, supporting them only if they meet ACIAR's stringent criteria.

Among the first projects approved are studies aimed at the development of highyielding cultivars of the pigeon pea, a crop particularly suited to semi-arid environ- ments in Asia, the development of a computer-based system to assist in the identification of virus diseases of plants, research into the use of rice straw as an animal feed in India and a series of projects on the storage of grain in the tropics, to be carried out in the Phillippines, Malaysia and other South-East Asian countries. Further programmes are being prepared in biological nitrogen fixation, post-harvest technology of fruit, vegetables and fish, wheat genetics and pathology and farming systems in the South Pacific and Africa.

Vimala Sarma

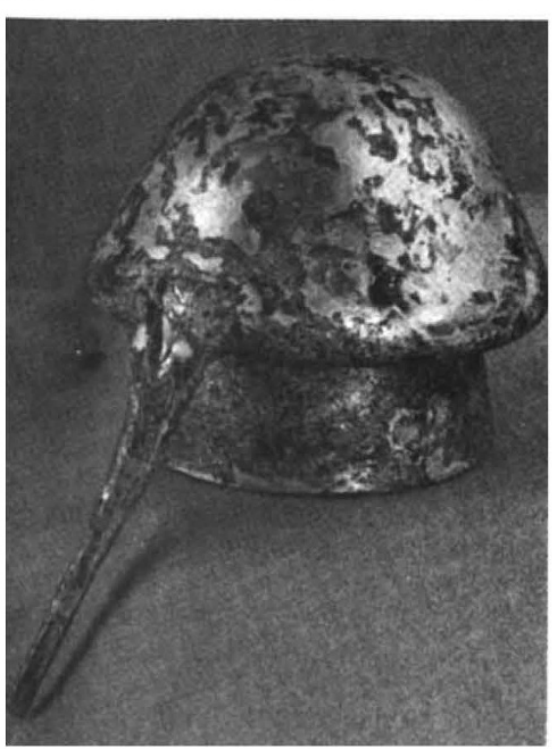

\section{Glass still around}

London's Science Museum this week puts on show four rare pieces of early chemical glassware. They were used by Arabs some time between the tenth and twelfth centuries for distillation and sublimation. The surface of the glass is weathered, giving a multi-coloured effect. Also on view in the exhibition which opens to the public on 5 May is new archaeological evidence. The earliest use of distillation techniques. 